\title{
Model for Vehicle to Home System with Additional Energy Storage for Households
}

\author{
Nikolay Hinov*(D), Vladimir Dimitrov and Gergana Vacheva \\ Department of Power Electronics, Technical University of Sofia, 1000 Sofia, Bulgaria; dimitrov@tu-sofia.bg (V.D.); \\ gergana_vacheva@tu-sofia.bg (G.V.) \\ * Correspondence: hinov@tu-sofia.bg; Tel.: +359-29652569
}

check for updates

Citation: Hinov, N.; Dimitrov, V.;

Vacheva, G. Model for Vehicle to

Home System with Additional Energy Storage for Households. Electronics 2021, 10, 1085. https:// doi.org/10.3390/electronics10091085

Academic Editors: Gabriele Grandi and Sergio Busquets-Monge

Received: 16 March 2021

Accepted: 1 May 2021

Published: 4 May 2021

Publisher's Note: MDPI stays neutral with regard to jurisdictional claims in published maps and institutional affiliations.

Copyright: (c) 2021 by the authors. Licensee MDPI, Basel, Switzerland. This article is an open access article distributed under the terms and conditions of the Creative Commons Attribution (CC BY) license (https:// creativecommons.org/licenses/by/ $4.0 /)$.

\begin{abstract}
Smart integration of the upcoming proliferation of electric forms of transport in our energy system is the key in order to make it more robust and ready for a greener future. As such, technologies as Vehicle to Home are key in order to optimize the house consumption on an individual level. This paper develops the key blocks of a modified Vehicle to Home system, where in addition to the EV, a stationary battery pack is added. The paper presents models for household consumption, bidirectional AC/DC converter, its control system, dc/dc controllers, and their controllers. The goal is to design a system capable of consuming a desired power over time from the AC grid. Any energy difference is used to charge or discharge the available energy sources. As such, optimal control strategies are developed for the control of both the charging/discharging process. The presented optimized models allow for system level simulation for several weeks on a typical computer. Using this model some allows bot sizing the dc energy storage needed, along with comparison of different control algorithms for the power converters.
\end{abstract}

Keywords: electric vehicles; V2H system; power conversion; control systems

\section{Introduction}

As Europe strives to make its economy more sustainable through support of programs such as the European green deal [1], vast financial support is provided for people to change their preferred ways of transportation and living habits. Incentives to use more forms of electric transport are widely implemented. As for the homes themselves, investments are suggested to make them more smarter and energy efficient [1]. In order to succeed in these endeavors the whole energy generation and transportation system must be rethought. The energy generated thought green sources (such as PV and Wind) is intermittent in nature. This means that in the near future, when the dependence on this kind of energy becomes even more significant, every consumer might need to think about optimal time of energy consumption. For this reason, many ideas are available to interconnect the mobile dc energy sources available in various electric vehicles to the grid. Technologies such as Vehicle to Grid (V2G), Vehicle to Home (V2H), or Vehicle to Vehicle (V2V) are discussed in the literature [2-4].

Looking at the problem from the bottom (on the lowest consumer level) - a typical household, technologies such as zero-energy building can lead to very efficient solutions to the above presented problems. Using electric vehicles as an additional energy source in such cases has been presented previously, as for example [5]. In such a scenario the integration of only the EV might not be enough to obtain optimal consumption (including zero) from the grid [6]. The system can be improved by combining the vehicle battery storage, with an additional stationary energy source. This can allow for the whole system to become more robust and reliable on the one hand, and more economically efficient on the other. This strategy might be plausible, provided there is enough incentive to consume energy during specific times of the day. This is the main scenario that will be discussed in this paper. 
Models for V2H systems have been presented in numerous papers [7-10]. These papers are concerned with the optimal energy sizing [5] or algorithm $[3,7,8]$ for controlling such a system, but without detailed simulation models for the power converters. On the other hand, there are papers (for example [11]), where models for individual converters are presented, but without full integration with other models. Controlling the process of energy conversion between the battery of the electric vehicle when used as an energy storage element in a V2H system is the topic of [12-14]. Using artificial intelligence for the control implementation, as shown in $[15,16]$ is also an interesting proposition.

The approach adapted in this paper combines the two levels of modeling in a single concept. Individual models for the power converters are presented, along with control algorithm for the whole system. The model is optimized and allows for simulation in the timespan of several days on a standard PC, so it can be used to estimate the required energy from the various energy storage devices or test various charging algorithms for the vehicle [3].

In the general theme of the "Green Deal", and the mission to lower the overall emission levels, the main question of how to integrate various electric transport vehicles in micro- and nanogrids is equally important. These small-scale grids that are decentralized provide many unique problems. Various publications on these topics go into details on how to integrate and control such grids on a more systematic level, the question of their stability and optimization are given in [17-24]. The primary energy sources used in both electric vehicles and stationary battery banks are based on lithium batteries. Their optimal exploitation, methods for overall cost reduction, and ways to improve overall efficacy during conversion is also a topic of scientific interest [25-28].

This paper proposes the use of a secondary energy source that complements the energy from the electric vehicle. This secondary energy source that is stationary and can be installed on premise can facilitate the consumption of a predetermined waveform from the ac grid, thus providing optimal energy consumption. On the other hand, the introduction of an additional energy storage element allows for optimum energy consumption not only from the grid (or some other decentralized power source) but also from the EV battery. This is an important additional advantage of the topology, as the battery state of health can be improved and allow for longer exploitation period.

The paper is structured as follows: In the next section the main system is presented, along with detailed models for each of the main subsystems. Moreover, the control algorithm for the whole system is presented. A discussion on the designed control algorithm is also given. Section 3 presents a simulation of the developed system for a typical household consumption and system parameters for a 2 day period. Discussion of the obtained results is provided in Section 4, and finally Section 5 concludes the paper.

\section{System Model}

The presented V2H system contains three primary subsystems that needs to be modeled. These are-a model for the household (more specifically its power demand), the energy storage blocks and their power converters (the electric vehicle and a battery bank), and finally a power electronic block that can convert energy between the dc and ac bus. A control system for each converter is also shown. The block diagram of the designed system is shown in Figure 1.

The paper presents models for each of the separate subsystems:

- Bidirectional AC/DC converter-the block between the ac side and both dc storage sources.

- An electric vehicle and the involved power converter charging the battery. This vehicle is assumed to be able to charge itself from a dc bus.

- A stationary battery bank.

- A model for the power consumption of the typical household.

- Control systems for each of the power converters. 


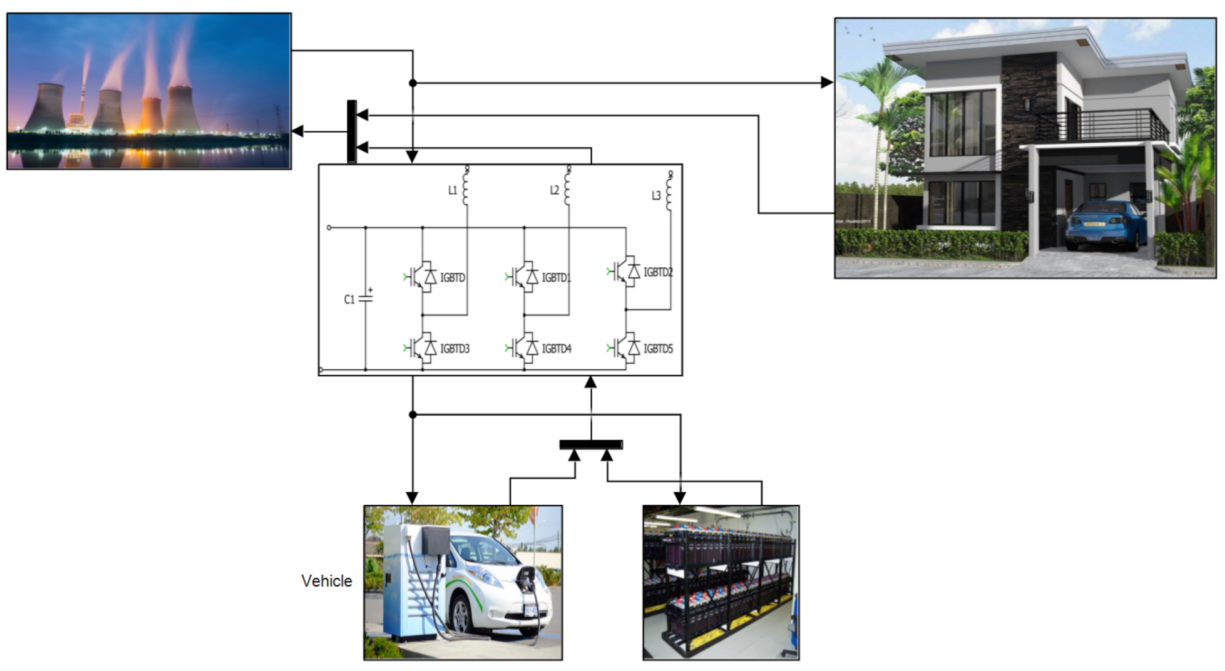

Figure 1. Block diagram of the modelled system.

The implementational details for each of the models will be discussed in the next subsections.

\subsection{Bidirectional AC/DC Converter Model}

The schematic of the modeled converter is shown in Figure 2. It is a typical three-phase full bridge converter that can act as a boost type PFC rectifier, or an inverter depending on the directional of energy flow. The load in the system on the dc side is represented as a current source IL that can come from the battery bank or the vehicle battery and can be both positive or negative.

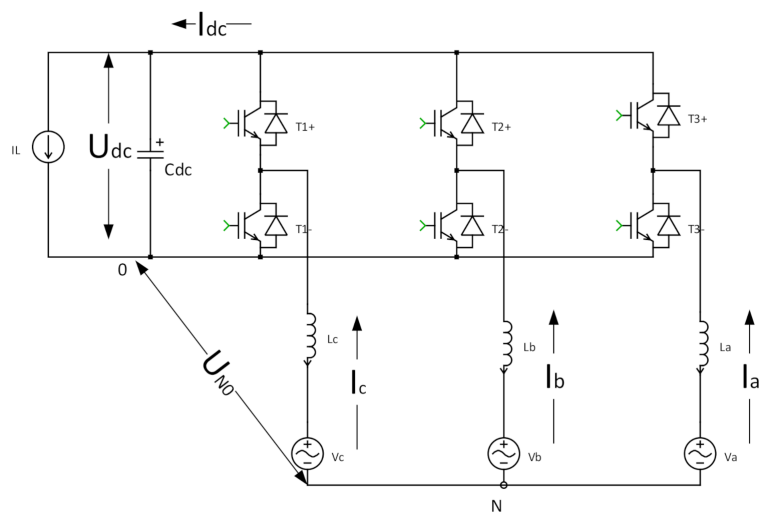

Figure 2. Block diagram of the bidirectional ac/dc converter.

For the system, after introducing the switching functions $F_{a}, F_{b}, F_{c}$, the following equations can be written:

$$
\begin{gathered}
V_{a}=L_{a} \frac{d I_{a}}{d t}+F_{a} U_{d c}+U_{N 0} \\
V_{b}=L_{b} \frac{d I_{b}}{d t}+F_{b} U_{d c}+U_{N 0} \\
V_{c}=L_{c} \frac{d I_{c}}{d t}+F_{c} U_{d c}+U_{N 0} \\
\mathrm{C}_{\mathrm{dc}} \frac{\mathrm{d} U_{\mathrm{dc}}}{\mathrm{dt}}=\mathrm{i}_{\mathrm{rec}}-\mathrm{I}_{\mathrm{dc}}
\end{gathered}
$$


Assuming the system is balanced, so $V_{a}+V_{b}+V_{c}=0$ and $\frac{d I_{a}}{d t}+\frac{d I_{b}}{d t}+\frac{d I_{c}}{d t}=0$ and summing the three equations for the ac side and extracting $U_{N 0}$ the following set of equations is obtained:

$$
\begin{gathered}
\mathrm{V}_{a}=\mathrm{L}_{a} \frac{\mathrm{dI}_{a}}{\mathrm{dt}}+\mathrm{U}_{\mathrm{dc}}\left(\mathrm{F}_{a}-\frac{1}{3}\left(\mathrm{~F}_{\mathrm{a}}+\mathrm{F}_{\mathrm{b}}+\mathrm{F}_{\mathrm{c}}\right)\right) \\
V_{b}=L_{b} \frac{d I_{b}}{d t}+U_{d c}\left(F_{b}-\frac{1}{3}\left(F_{a}+F_{b}+F_{c}\right)\right) \\
V_{b}=L_{c} \frac{d I_{c}}{d t}+U_{d c}\left(F_{c}-\frac{1}{3}\left(F_{a}+F_{b}+F_{c}\right)\right) \\
C_{\mathrm{dc}} \frac{\mathrm{d} \mathrm{U}_{\mathrm{dc}}}{\mathrm{dt}}=\mathrm{i}_{\mathrm{a}} \mathrm{S}_{\mathrm{a}}+\mathrm{i}_{\mathrm{b}} \mathrm{S}_{\mathrm{b}}+\mathrm{i}_{\mathrm{c}} \mathrm{S}_{\mathrm{c}}-\mathrm{I}_{\mathrm{dc}}
\end{gathered}
$$

Introducing the $d q 0$ transform for steady-state operation:

$$
K_{d q 0}=\frac{2}{3}\left[\begin{array}{ccc}
\cos \omega t & \cos \left(\omega t-\frac{2 \pi}{3}\right) & \cos \left(\omega t-\frac{4 \pi}{3}\right) \\
\sin \omega t & \sin \left(\omega t-\frac{4 \pi}{3}\right) & \sin \left(\omega t-\frac{4 \pi}{3}\right) \\
\frac{1}{2} & \frac{1}{2} & \frac{1}{2}
\end{array}\right]
$$

Assuming $L_{a}=L_{b}=L_{c}=L$ the system dynamics in this reference frame can be written as:

$$
\begin{gathered}
\mathrm{V}_{q}=L \frac{\mathrm{dI}_{q}}{\mathrm{dt}}+\omega L I_{d}+\mathrm{U}_{\mathrm{dc}}\left(\mathrm{F}_{q}-\frac{1}{3}\left(\mathrm{~F}_{\mathrm{q}}+\mathrm{F}_{\mathrm{d}}+\mathrm{F}_{0}\right)\right) \\
\mathrm{V}_{d}=L \frac{\mathrm{dI}_{d}}{\mathrm{dt}}-\omega L I_{q}+\mathrm{U}_{\mathrm{dc}}\left(\mathrm{F}_{d}-\frac{1}{3}\left(\mathrm{~F}_{\mathrm{q}}+\mathrm{F}_{\mathrm{d}}+\mathrm{F}_{0}\right)\right) \\
\mathrm{V}_{0}=\mathrm{L} \frac{\mathrm{dI}_{d}}{\mathrm{dt}}+\mathrm{U}_{\mathrm{dc}}\left(\mathrm{F}_{0}-\frac{1}{3}\left(\mathrm{~F}_{\mathrm{q}}+\mathrm{F}_{\mathrm{d}}+\mathrm{F}_{0}\right)\right) \\
\mathrm{C}_{\mathrm{dc}} \frac{\mathrm{dU} \mathrm{dc}}{\mathrm{dt}}=\frac{3}{2}\left(\mathrm{I}_{\mathrm{d}} \mathrm{F}_{\mathrm{d}}+\mathrm{I}_{\mathrm{q}} \mathrm{F}_{\mathrm{q}}+\mathrm{I}_{0} \mathrm{~S}_{0}\right)-\mathrm{I}_{\mathrm{dc}}
\end{gathered}
$$

These equations form the bases of the model, which is shown in Figure 3.

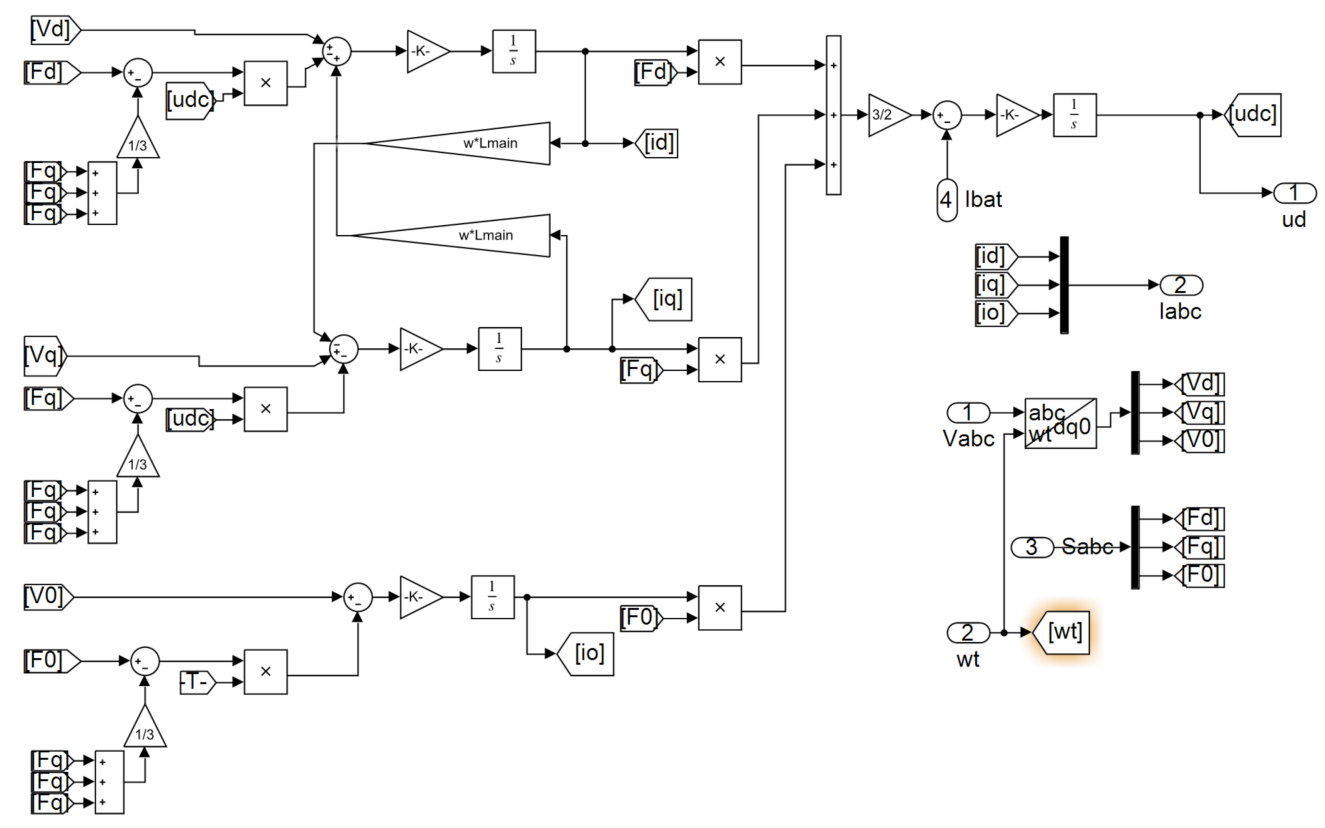

Figure 3. Power converter Model.

\subsection{Bidirectional DC/DC Converter Model}

The bidirectional converter used in the battery bank subsystem and the vehicle subsystem is a two transistor bidirectional topology shown in Figure 4. 


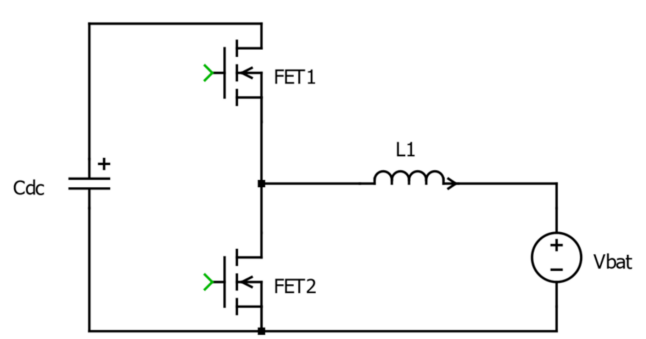

Figure 4. Bidirectional Converter for modelling the battery and vehicle subsystems.

For the system, after introducing the switching functions $F_{d c}$, the following equation can be written:

$$
\mathrm{U}_{d c}=\mathrm{L}_{o} \frac{\mathrm{dI}_{o}}{\mathrm{dt}}+\mathrm{U}_{b a t} \mathrm{~F}_{d c}
$$

The model for this equation is shown in Figure 5.

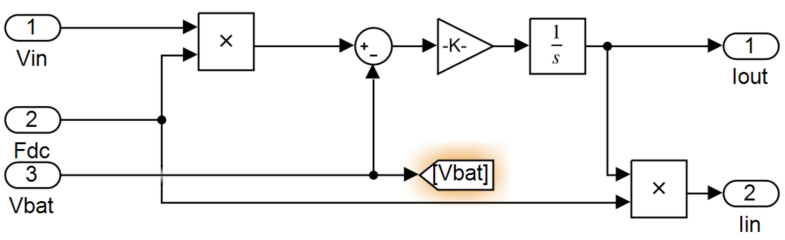

Figure 5. Model of the bidirectional converter.

\subsection{Household Model}

The household is modeled by its active and reactive power consumption. Based on these tabulated values, assuming the three phase voltages form a balanced set and transforming the equations in the $d q 0$ frame (as in the ac/dc converter) allows for the calculation of the consumed currents:

$$
\begin{aligned}
& I_{d}=\frac{2\left(P U_{d}+Q U_{q}\right)}{U_{d}^{2}+U_{q}^{2}} \\
& I_{q}=\frac{2\left(P U_{q}-Q U_{d}\right)}{U_{d}^{2}+U_{q}^{2}}
\end{aligned}
$$

From these the current consumption in the standard abc reference frame can easily be calculated. The model is shown in Figure 6.

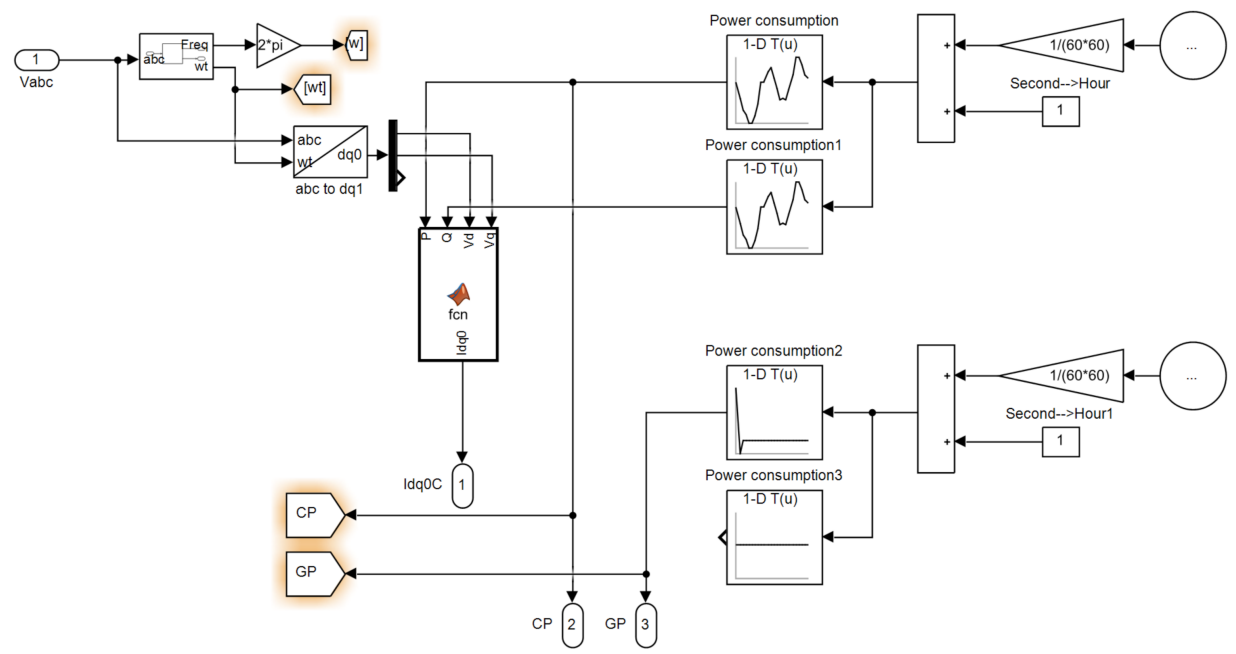

Figure 6. Household model. 


\subsection{Control Algorithms}

The control system for both converters that has been implemented in Stateflow is shown in Figure 7. Each of the converters have three levels of control 0, 1 or 2 . When its input is 0 the converter returns energy back to the dc bus. When the input is 1 , then it does not function (zero current consumed or returned to the dc bus). The third case covers time intervals when current needs to be consumed from the dc bus in order to charge the energy storage. The amount of energy consumed depends on the available energy.

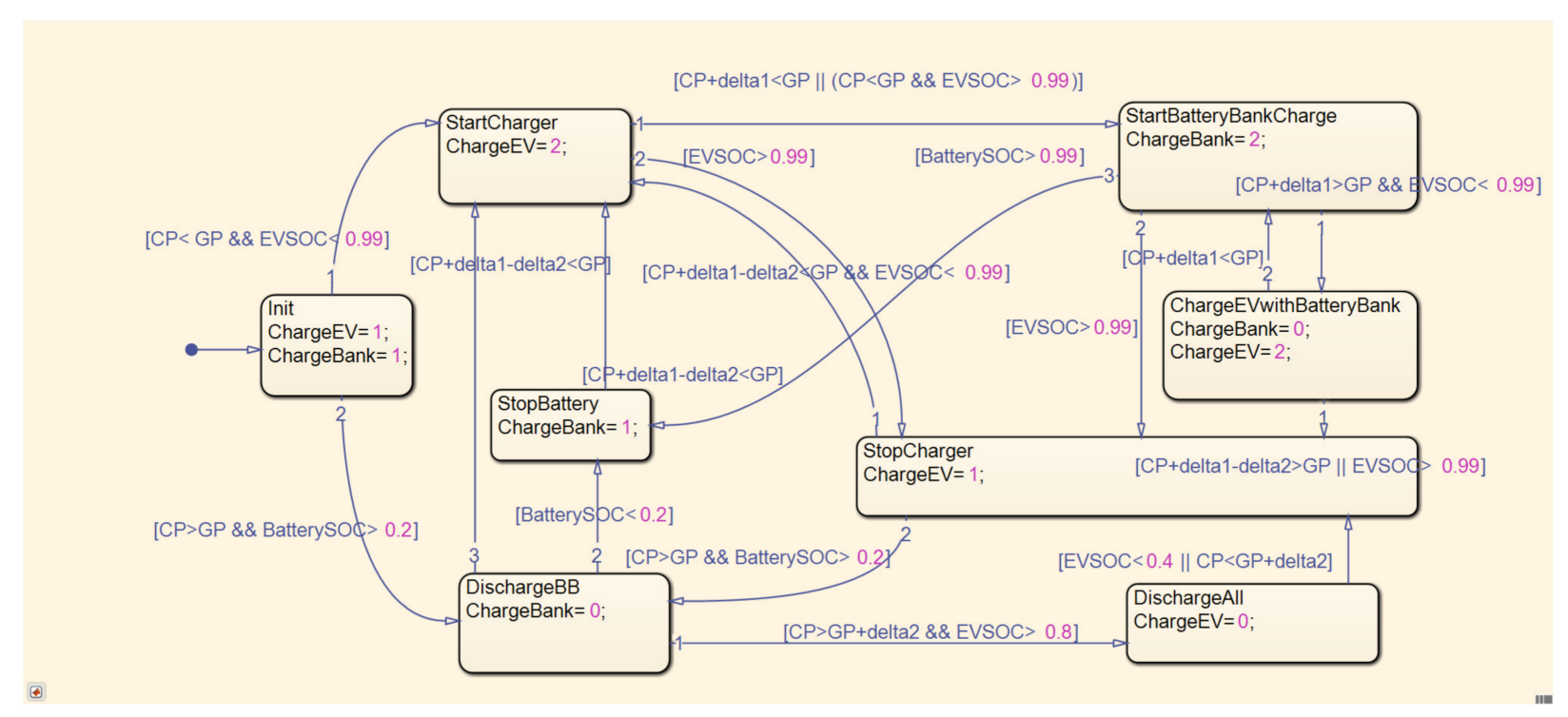

Figure 7. General Control Algorithm.

Which command signal is generated depends on the difference between the Consumed power from the household and a reference waveform for ac line consumption. This waveform sets the power that the household wants to consume from the electrical grid. This curve can be optimized depending on the electricity prices or some other parameter. The general control strategy proposed is as follows:

- When the input power is larger than the one needed from the household, the EV is charged first with constant power. Any excess above this is transferred to the battery stack. If there is excess input power, but not enough to charge the EV, then the battery bank is discharged to add the needed power.

- When the input power is lower than the one needed for the household, first the battery stack supplies it. The constraints are maximum dept of discharge of its battery and maximum power supplied. When any of these is violated either the EV's battery can supply some additional power (SOC is above $80 \%$, and there is a limit to the maximum power than can be supplied) or the battery bank works with limited discharge power.

\subsection{Battery Stack Converter Control}

As was discussed in the overall control design goal there are three states that the converter can be-off, $\mathrm{u}=1$; charging the battery, $\mathrm{u}=2$; or discharging the battery and returning energy to the dc bus, $u=0$. The control in each of these cases is made by independent subblocks. A flowchart that shows the basic operation of the control system is shown in Figure 8, while the implemented control algorithm in Figure 9. 


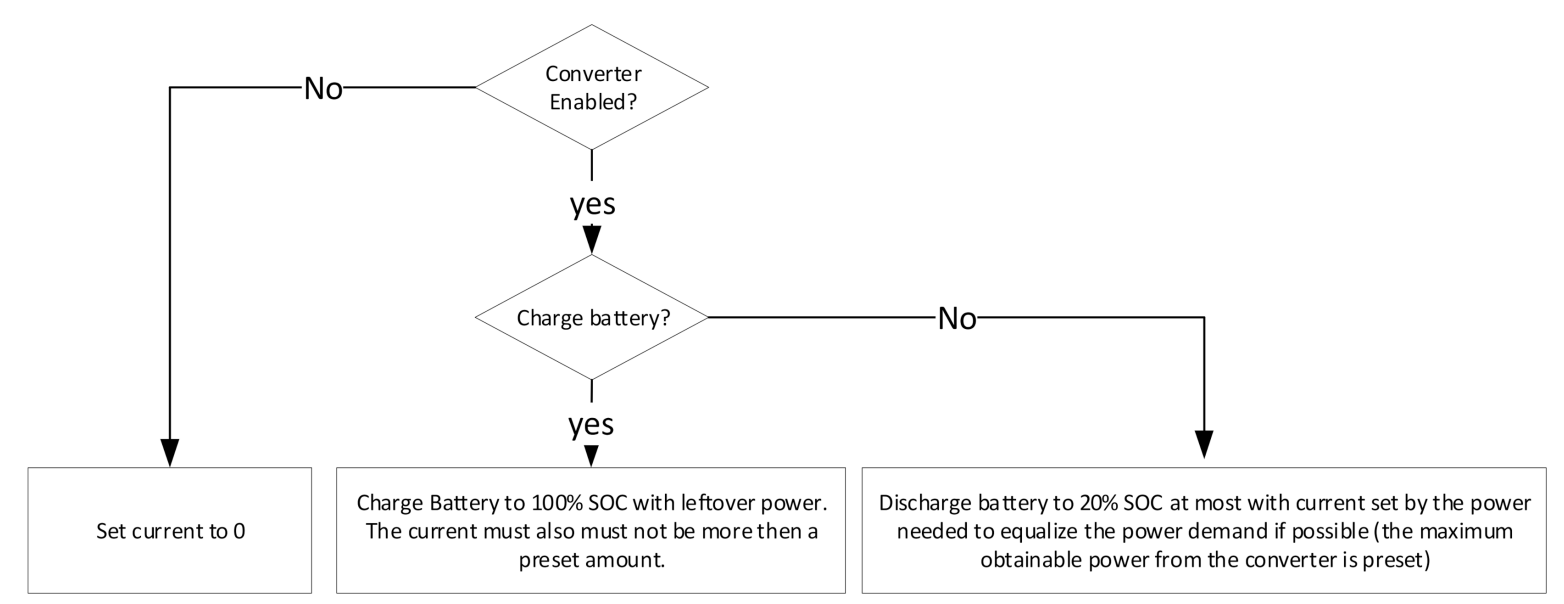

Figure 8. A flowchart discussing the algorithm of the converter connected to the Battery Bank.

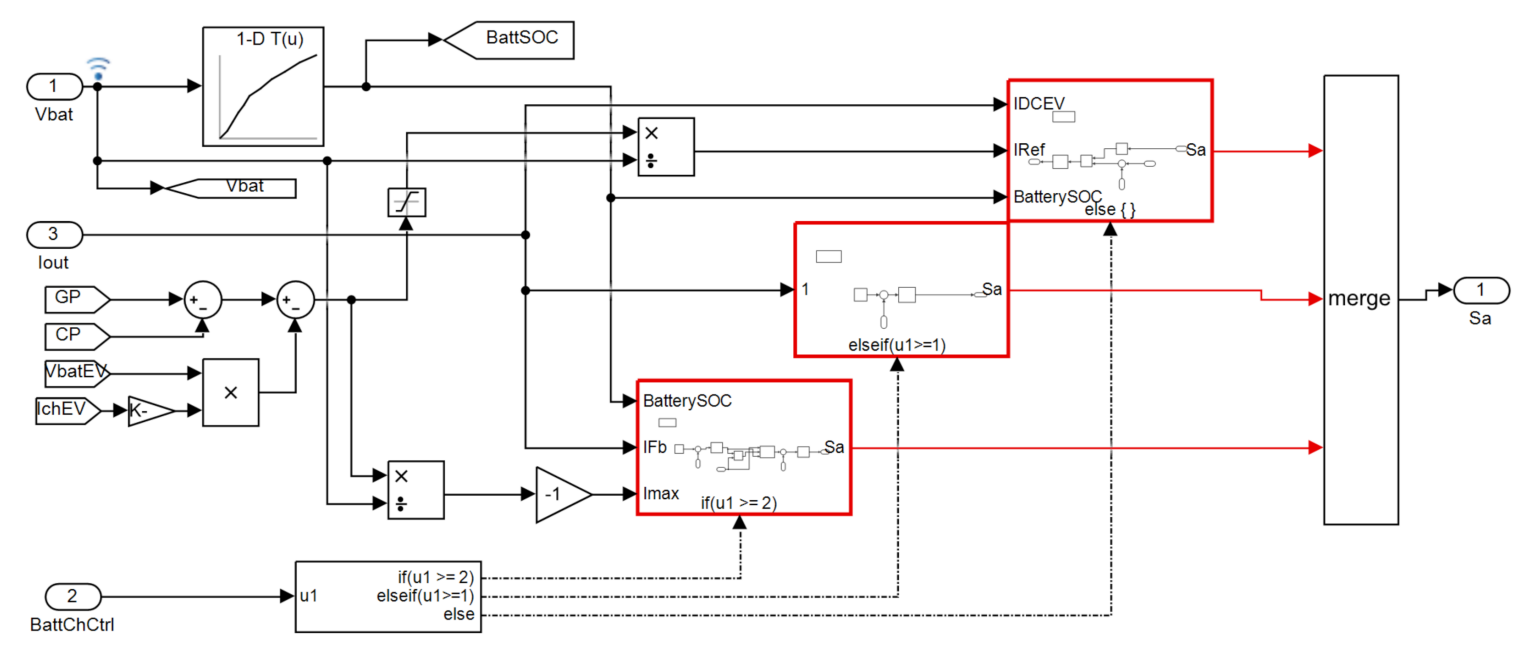

Figure 9. Control Algorithm for battery bank.

When in state 2 (the battery is charged) the control subsystem is shown in Figure 10. The control algorithm charges the battery to $100 \%$ SOC with current that is not more than the maximum available. This maximum available current (IbatMax) is calculated by dividing the difference between the consumed and generated power and the dc bus voltage.

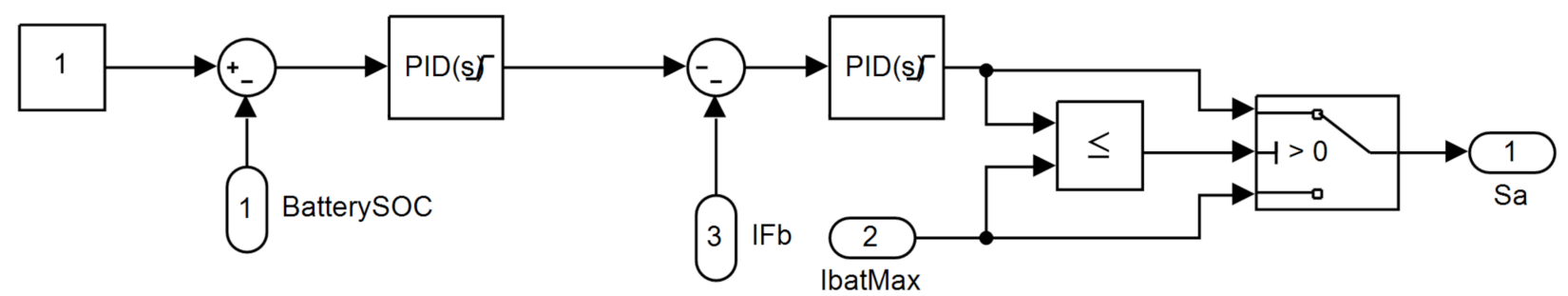

Figure 10. Control algorithm when charging the battery bank.

When the battery is discharged (state 0 ) the control subsystem is regulating the current out of the battery (again obtained as the difference between the generated and consumed power is divided by the battery bank voltage) until the SOC of the battery is reduced to a predetermined level. The control algorithm is shown in Figure 11. 


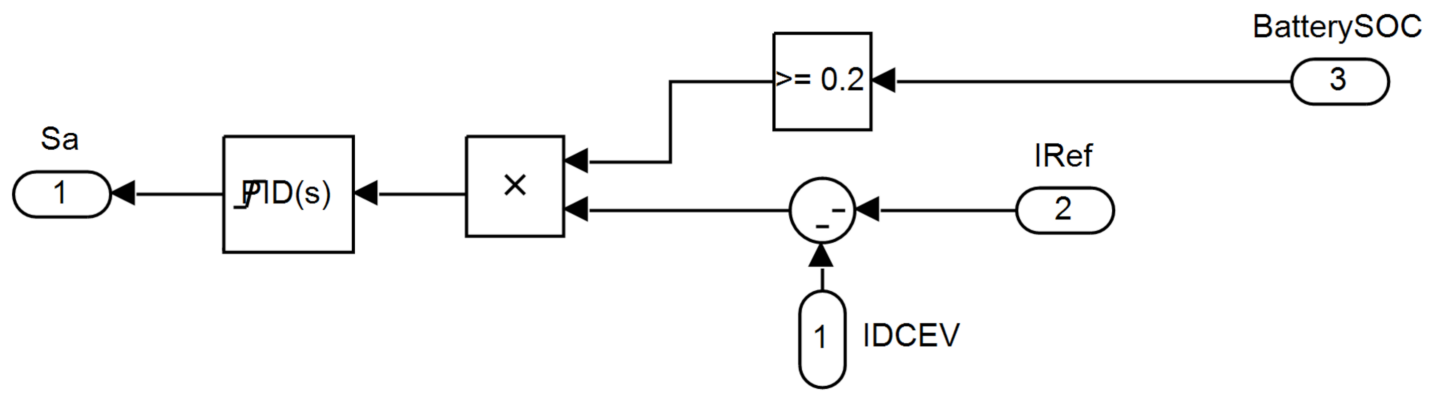

Figure 11. Control algorithm when discharging the battery bank.

\subsection{Vehicle Converter Control}

The control system of the vehicle charger has analogous requirements to the one that was presented above. It is shown in Figure 12.

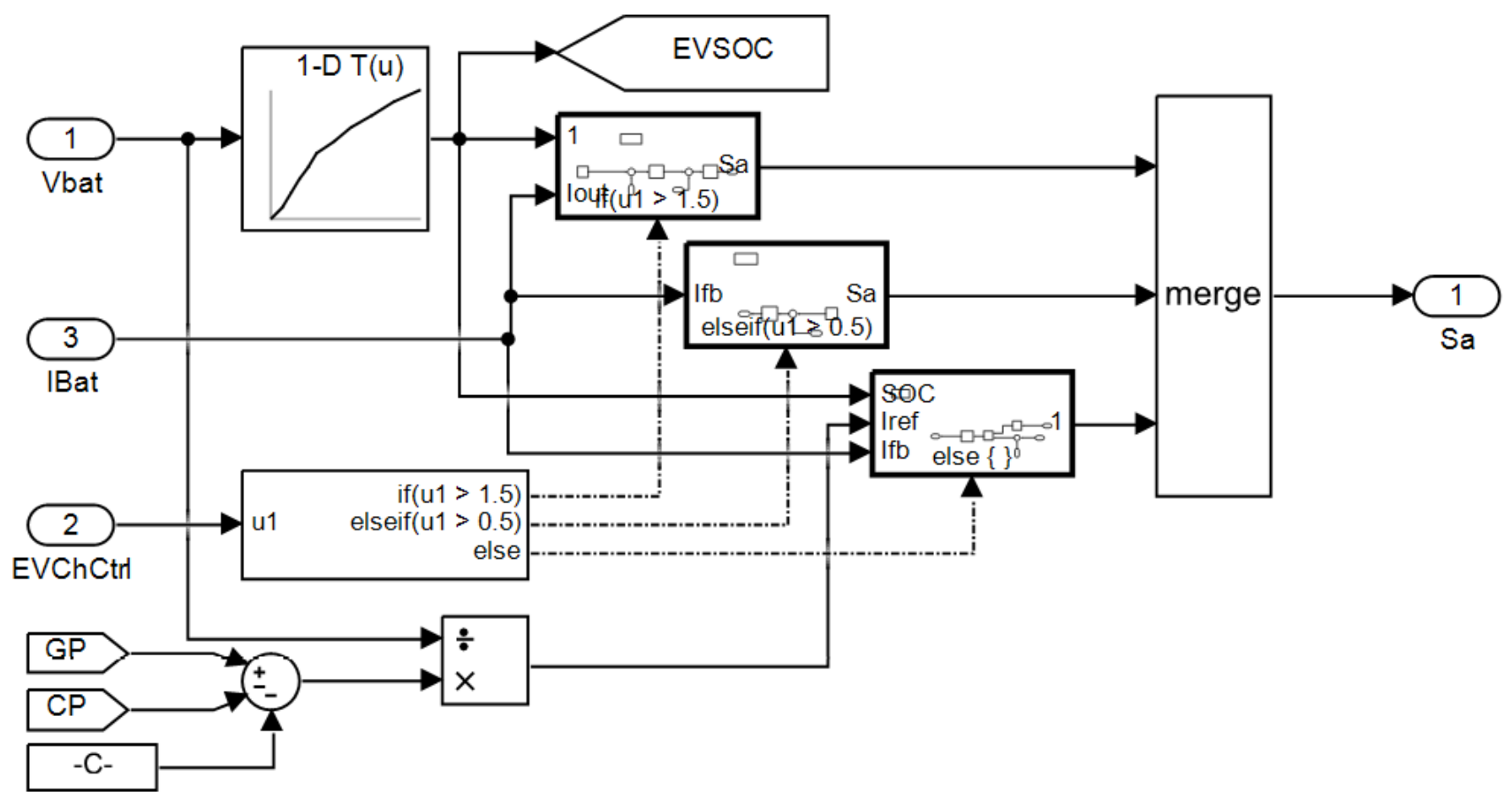

Figure 12. Control algorithm of the vehicle charger.

The main difference is that when the vehicle is charging its battery (state 2) the consumed power is assumed to be constant as usually the onboard charger has fixed power capabilities. When the battery is discharged the current reference is calculated as the power required from the vehicle (the power set to be consumed by the mains minus the required one from the household and the current one supplied from the battery bank) divided by the dc bus voltage. A simple flowchart that presents the developed model is shown in Figure 13. 


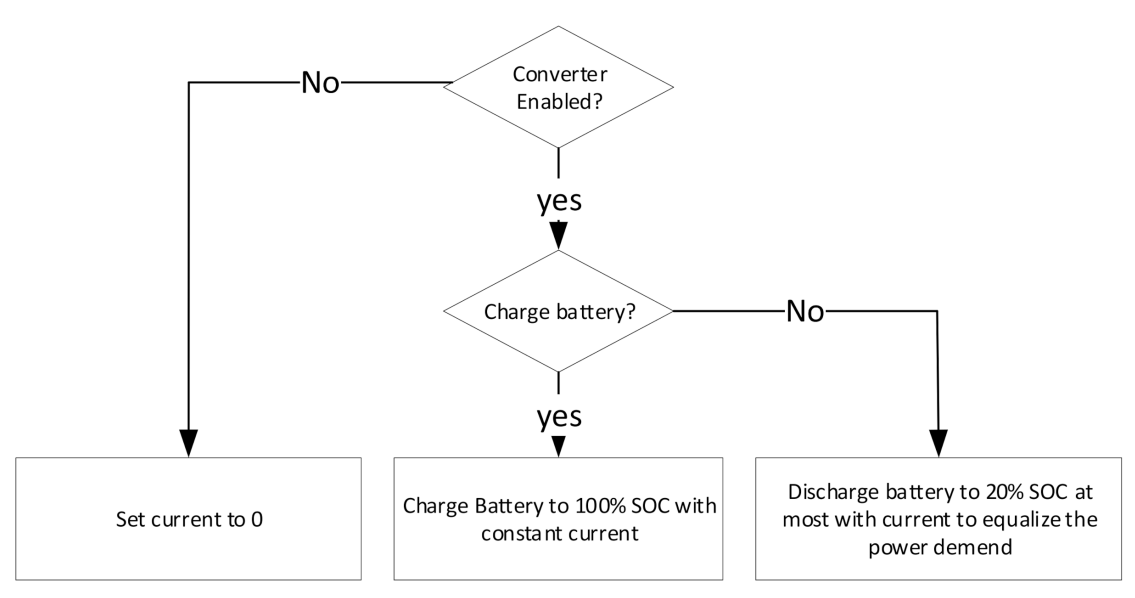

Figure 13. A flowchart discussing the algorithm of the converter connected to the EV.

\subsection{AC/DC Converter}

The control system for the converter is the standard decoupled control presented in Figure 14 [6]. The main idea behind this control algorithm is to remove the disturbance from $\omega L I_{d}$ and $\omega L I_{q}$ parts and obtain a simplified dependence of current charging the output capacitor only from the DQ transformed currents (that are the control goal). The refences for the Id and Iq currents can be set accordingly to control the Active and Reactive power consumed from the ac bus. As for the current application (small households) the reactive power is not measured, so the Iq and I0 current references are set to zero.

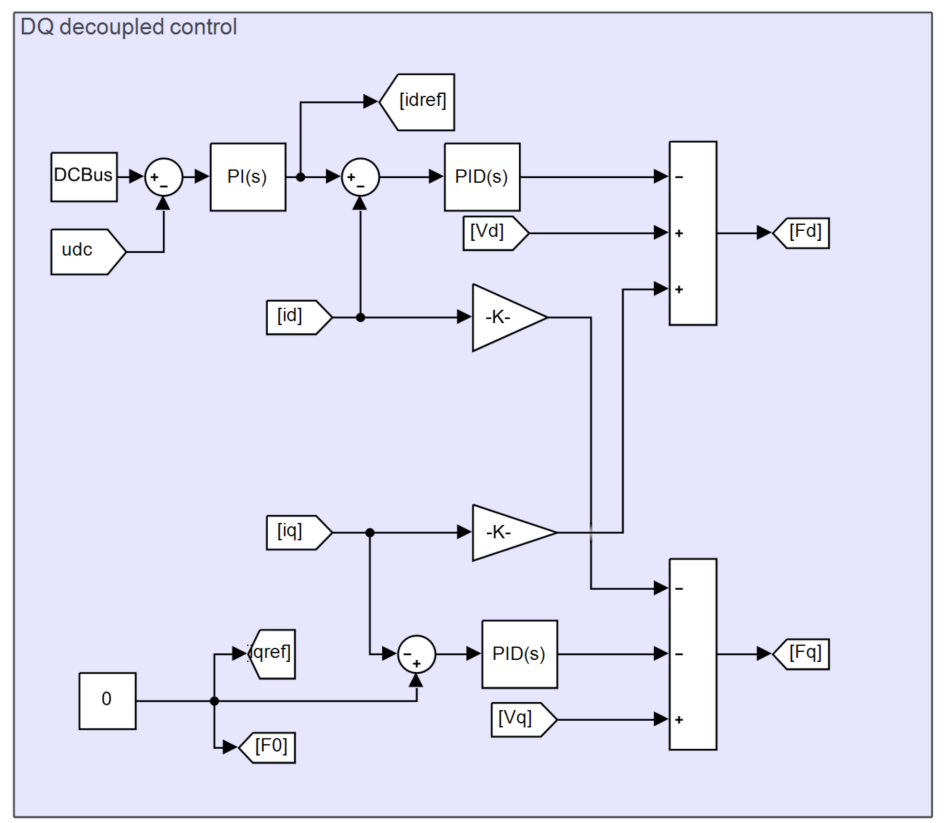

Figure 14. Control algorithm of the power converter.

\section{Results}

In order to verify the whole system, the following main requirements must be set:

- The power consumption of the household, along with a targeted power consumption from the ac grid

- $\quad$ Battery bank size

- Electric Vehicle battery charger nominal power

As for the first requirement the load schedule is shown in Figure 15. 


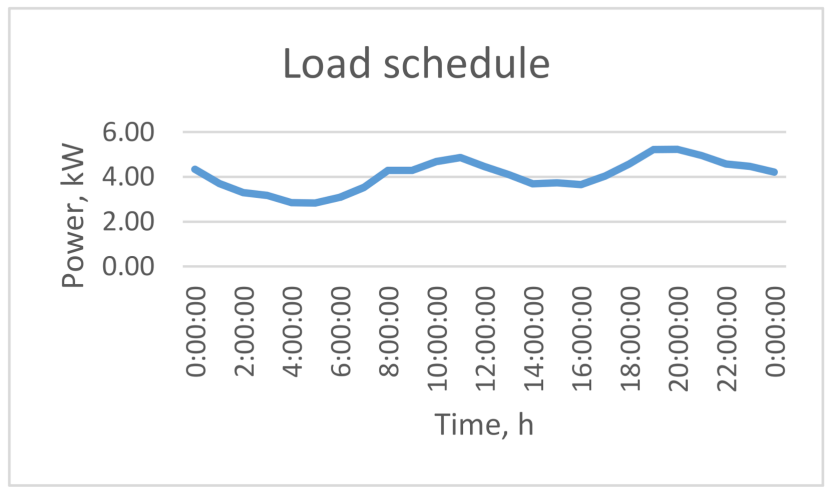

Figure 15. Active power consumed from the household for a typical day.

Other system parameters are given in Table 1.

Table 1. Key system parameters.

\begin{tabular}{cc}
\hline Parameter & Value \\
\hline BBank Ah & $280(\mathrm{Ah}) \cong 450 \mathrm{~V}$ \\
Vehicle Battery Ah & $112(\mathrm{Ah}) \cong 500 \mathrm{~V}$ \\
BBank peak power & $2(\mathrm{~kW})$ \\
Vehicle Charge power & $3.5(\mathrm{~kW})$ \\
\hline
\end{tabular}

The load profile for 2 days of requested AC grid power is given in Figure 16. The used profile is based on the idea to consume more power from the grid at night, when the price is lower. The load balancing during the day is taken care from the energy sources.

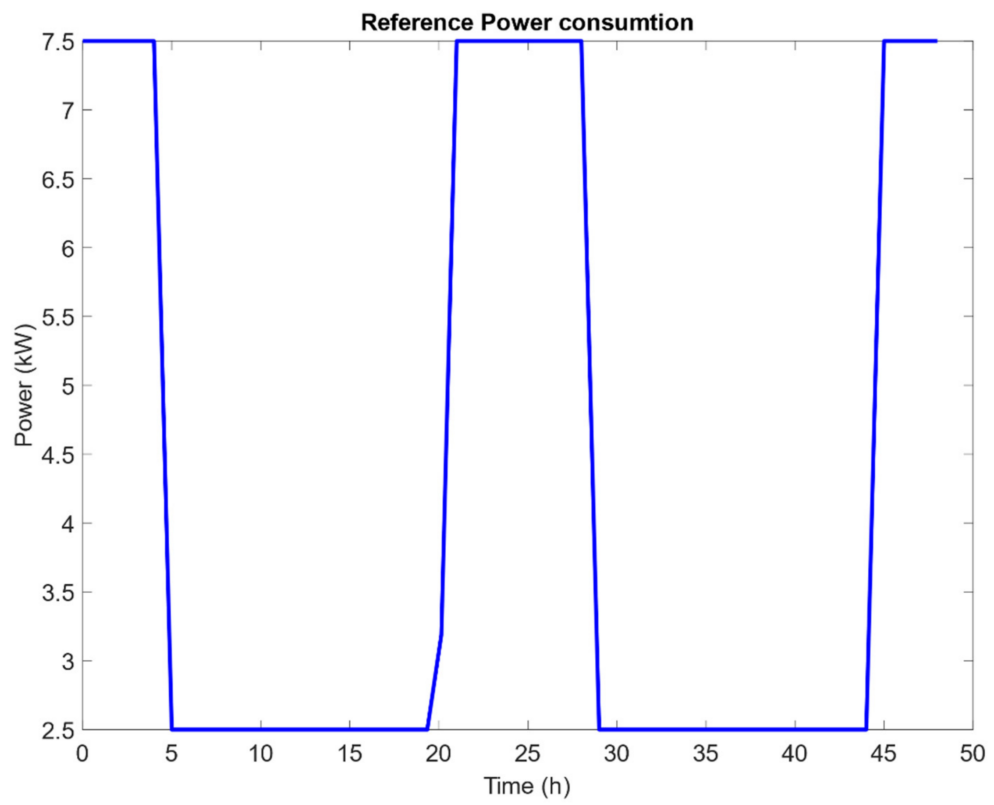

Figure 16. Requested AC Power (kW).

Waveforms for the Ordered (blue) and real consumed power compared to the real power consumption of the load (black) based on a 2-day period simulation data from the model are shown in Figure 17. On the left of the graph the back is the real ac consumption of the household (as per Figure 15). On the right side are the currents from the two energy sources. If the current is positive, then power is consumed from the energy source. This means for example that during the first day ( $5 \mathrm{~h}$ to $18 \mathrm{~h}$ ) power is consumed from the 
battery bank in order to balance the power demand. The graph also shows the current from the electric vehicle battery. Again, negative values mean that current is delivered (for example during the first night ( 0 to $5 \mathrm{~h}$ ).
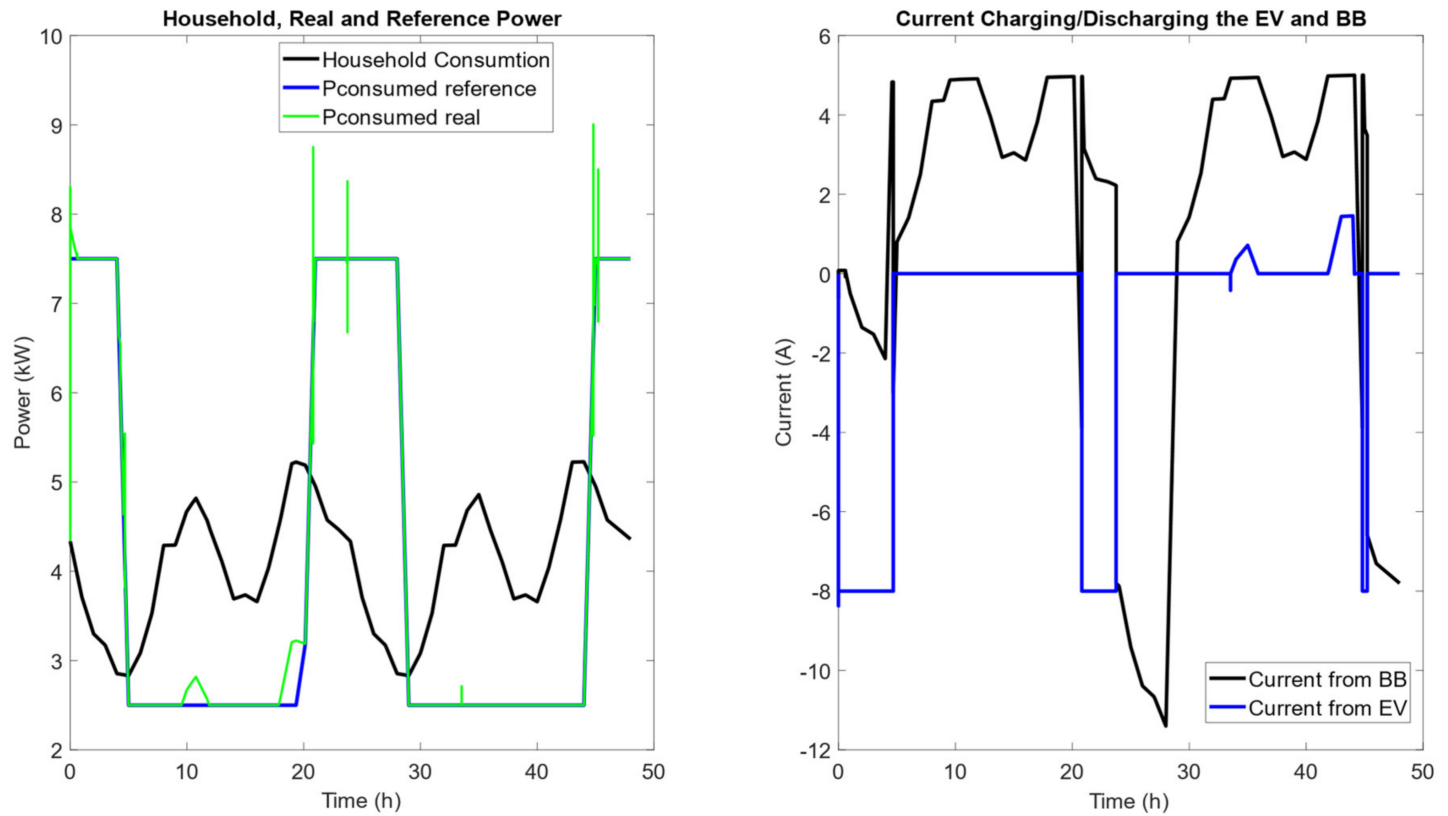

Figure 17. System simulation for 2 days (left) AC power reference and real consumption (right) battery currents waveforms.

The system state for both converters and battery SOC for both the EV and battery bank are shown in Figure 18.
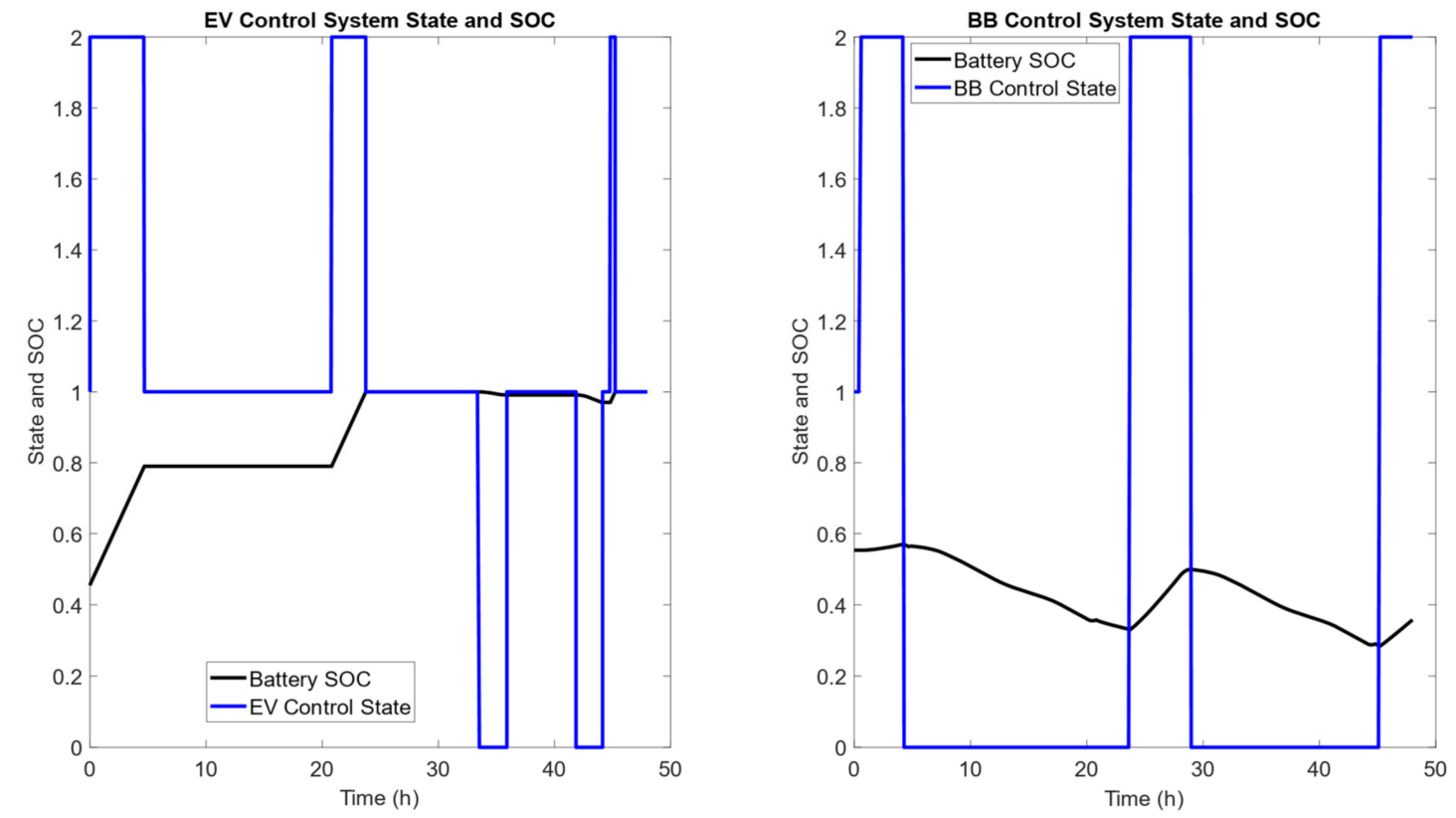

Figure 18. System state and Battery SOC the (left) EV converter, (right) battery bank.

Finally, the DC bus voltage and the energy supplied (positive) and absorbed from the battery of the EV and battery bank are shown in Figure 19. 

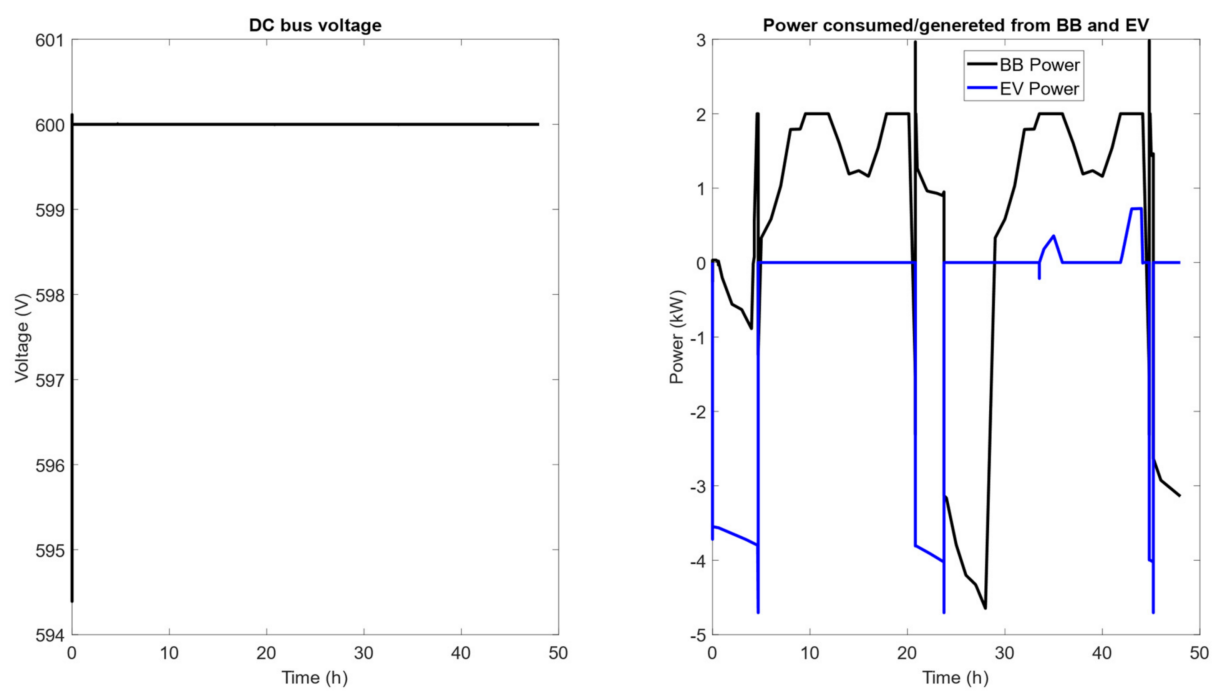

Figure 19. (left) DC bus voltage and (right) energy supplied (positive) and returned to the battery of the EV (red) and Battery Bank (black) in (kW).

\section{Discussion}

The presented waveforms give results for the required power demand/supply from both converters. As can be seen from the right side of Figure 19 during the first night ( 0 to around $6 \mathrm{~h}$ ) energy is delivered to both the battery bank and the EV is charged. Then, as the day tariffs kick of (rapid decrease of the reference ac grid consumption shown in Figure 16) the EV charging is stopped and the battery bank starts discharging, in order to keep the energy balance.

For the first day ( 6 to $20 \mathrm{~h}$ ) the SOC of the battery is not enough to allow its discharge, so the only power source is the battery bank. As its peak power is capped at $2 \mathrm{~kW}$, there are two intervals during the day, where the reference curve cannot be reached. In this case some additional power is requested from the ac grid, and the reference curve is not followed. This can be seen in the left side of Figure 17 during $10 \mathrm{~h}$ and around the end of the day (18 to $20 \mathrm{~h}$ ).

When the second night comes an interesting thing happens. In the model, when the $\mathrm{EV}$ is charged, it is assumed that it cannot regulate its consumed power (constant charging current, as can be seen from Figure 17). This means that if the sum of the household consumption and EV charging power is greater that the reference curve, the battery bank must be discharged in order to keep the power balance. This happens during the second night, as the household consumption is higher during 20 to $23 \mathrm{~h}$. As the EV battery is charged during the second night all the excess power is transferred into charging the battery bank (until $29 \mathrm{~h}$ ).

As the battery of the EV is charged during the second day, this allows for its use in load balancing during the peak consumption during the end of the day (around $44 \mathrm{~h}$, and shortly around $35 \mathrm{~h}$ ) and this allows the system to consume only the reference power from the grid during the day.

A future iteration of the model may include the effects of battery aging on the system. Reserving some capacity (for example not charging the battery to a 100\%) might help the charge equalization process as the state of health $(\mathrm{SOH})$ drops over time.

\section{Conclusions}

Integration of a typical household with additional energy sources from an electric vehicle and a stationary battery bank allows for single home microgrid. This concept can be useful in a future zero-energy buildings in order to achieve Europe's goal of less emissions. The proposed secondary stationary energy storage that complements the EV battery can greatly reduce the on it. This also simplified the goal of achieving optimal consumption 
from the AC gird or some other decentralized energy source (such as a fuel-cell, PV panel, or a wind turbine). Such a system is called V2H. With the proposed structure a better integration of the available energy buffers in EVs is achieved. This allows for achieving a more sustainable energy grid by guaranteeing more constant energy consumption during the day.

The paper presented models for the three main subsystems of a V2H system-the power demand for a typical household, one for the energy storages involved (the battery of the electric vehicle and a battery bank), and models for the power converters that connects the dc and ac bus. The paper also presents the control systems for each power converter, along with the general system level algorithm. The one used in the paper is to consume a pre-set waveform from the grid that optimizes the cost of the electricity. The presented models allow for the simulation of the whole system for long interval of time and provides data for both system level demand and average requirements on power converter level. This is in contrast to other approaches taken [5-9,11], where either models that cover the detailed switching behavior of the power converters are used, or a block diagram on a system level is used, thus not including the effects of converter control systems. The advantage of the proposed approach to system research is that it allows a long time for simulation without the need for large computational resources (powerful hardware and work with big data), while obtaining satisfactory accuracy.

Future development of the model can easily incorporate reactive energy supply/demand for industrial sites, also possibly the design of a software system, which based on available data for energy generation to optimally size the energy source that is required. This will help consumers to assess the possible return of investment, when building such a system.

Author Contributions: N.H., V.D., and G.V. were involved in the full process of producing this paper including conceptualization, methodology, modelling, validation, visualization, and preparing the manuscript. All authors have read and agreed to the published version of the manuscript.

Funding: This research was funded by Bulgarian National Science Fund, grant number КП-06H37/25/18.12.2019.

Acknowledgments: This research is carried out within the framework of the project "Optimal design and management of electrical energy storage systems", КП-06-H37/25/18.12.2019, Bulgarian National Scientific Fund.

Conflicts of Interest: The authors declare no conflict of interest.

\section{References}

1. "European Commission Communication Sustainable Europe Investment Plan-European Green Deal Investment Plan", COM. January 2020. Available online: https:/ / eur-lex.europa.eu/legal-content/EN/TXT/?uri=CELEX\%3A52020DC0021 (accessed on 3 May 2021).

2. Liu, C.; Chau, K.T.; Wu, D.; Gao, S. Opportunities and Challenges of Vehicle-to-Home, Vehicle-to-Vehicle, and Vehicle-to-Grid Technologies. Proc. IEEE 2013, 101, 2409-2427. [CrossRef]

3. Neofytou, N.; Blazakis, K.; Katsigiannis, Y.; Stavrakakis, G. Modeling Vehicles to Grid as a Source of Distributed Frequency Regulation in Isolated Grids with Significant RES Penetration. Energies 2019, 12, 720. [CrossRef]

4. Saldaña, G.; San Martin, J.I.; Zamora, I.; Asensio, F.J.; Oñederra, O. Electric Vehicle into the Grid: Charging Methodologies Aimed at Providing Ancillary Services Considering Battery Degradation. Energies 2019, 12, 2443. [CrossRef]

5. Ancillotti, E.; Bruno, R.; Crisostomi, E.; Tucci, M. Using electric vehicles to improve building energy sustainability. In Proceedings of the 2014 IEEE International Electric Vehicle Conference (IEVC), Florence, Italy, 17-19 December 2014.

6. Tuttle, D.P.; Fares, L.; Baldick, R.; Webber, M.E. Plug-In Vehicle to Home (V2H) duration and power output capability. In Proceedings of the 2013 IEEE Transportation Electrification Conference and Expo (ITEC), Detroit, MI, USA, $16-19$ June 2013.

7. Akshya, S.; Ravindran, A.; Srinidhi, A.S.; Panda, S.; Kumar, A.G. Grid integration for electric vehicle and photovoltaic panel for a smart home. In Proceedings of the 2017 International Conference on Circuit, Power and Computing Technologies (ICCPCT), Kollam, India, 20-21 April 2017.

8. Shemami, M.S.; Alam, M.S.; Asghar, M.S.J. Load shedding mitigation through plug-in electric Vehicle-to-Home (V2H) system. In Proceedings of the 2017 IEEE Transportation Electrification Conference and Expo (ITEC), Chicago, IL, USA, 22-24 June 2017; pp. 799-804. [CrossRef] 
9. Naghibi, B.; Masoum, M.A.S.; Deilami, S. Effects of V2H Integration on Optimal Sizing of Renewable Resources in Smart Home Based on Monte Carlo Simulation. IEEE Power Energy Technol. Syst. J. 2018, 5, 73-84. [CrossRef]

10. Abessi, A.; Shirazi, E.; Jadid, S.; Shafie-khah, M. Sustainable and Resilient Smart House Using the Internal Combustion Engine of Plug-in Hybrid Electric Vehicle. Sustainability 2020, 12, 6046. [CrossRef]

11. Han, J.; Zhou, X.; Lu, S.; Zhao, P. A Three-Phase Bidirectional Grid-Connected AC/DC Converter for V2G Applications. J. Control Sci. Eng. 2020, 2020, 8844073. [CrossRef]

12. Uddin, K.; Jackson, T.; Widanage, W.D.; Chouchelamane, G.; Jennings, P.A.; Marco, J. On the possibility of extending the lifetime of lithium-ion batteries through optimal V2G facilitated by an integrated vehicle and smart-grid system. Energy 2017, 133, 710-722. [CrossRef]

13. Fuchs, G.; Lunz, B.; Leuthold, M.; Sauer, D.U. Technology Overview on Electricity Storage-Overview on the Potential and on the Deployment Perspectives of Electric Storage Technologies; Technical Report by ISEA; RWTH Aachen University: Aachen, Germany, 2012.

14. Gopalakrishnan, R.; Goutam, S.; Miguel Oliveira, L.; Timmermans, J.M.; Omar, N.; Messagie, M.; Van den Bossche, P.; Van Mierlo, J. A comprehensive study on rechargeable energy storage technologie. J. Electrochem. Energy Conver Storage 2016, $13,040801$. [CrossRef]

15. Berecibar, M. Machine-learning techniques used to accurately predict battery life. Nature 2019, 568, 325-326. [CrossRef]

16. Beaudin, M.; Zareipour, H. Home energy management systems: A review of modelling and complexity. Renew. Sustain. Energy Rev. 2015, 45, 318-335. [CrossRef]

17. Bracco, S.; Delfino, F.; Piazza, G.; Foiadelli, F.; Longo, M. Nanogrids with Renewable Sources, Electrical Storage and Vehicleto-Home Systems in the Household Sector: Analysis for a Single-Family Dwelling. In Proceedings of the 2019 IEEE Milan PowerTech, Milan, Italy, 23-27 June 2019; pp. 1-6. [CrossRef]

18. Wu, X.; Hu, X.; Moura, S.; Yin, X.; Pickert, V. Stochastic control of smart home energy management with plug-in electric vehicle battery energy storage and photovoltaic array. J. Power Sources 2016, 333, 203. [CrossRef]

19. Noel, L.; de Rubens, G.Z.; Kester, J.; Sovacool, B.K. Beyond emissions and economics: Rethinking the co-benefits of electric vehicles (EVs) and vehicle-to-grid (V2G). Transp. Policy 2018, 71, 130-137. [CrossRef]

20. Paterakis, N.G.; Erdinç, O.; Pappi, I.N.; Bakirtzis, A.G.; Catalão, J.P.S. Coordinated operation of a neighborhood of smart households comprising electric vehicles energy storage and distributed generation. IEEE Trans. Smart Grid 2016, 7, $2736-2747$. [CrossRef]

21. Tan, K.M.; Ramachandaramurthy, V.K.; Yong, J.Y. Integration of electric vehicles in smart grid: A review on vehicle to grid technologies and optimization techniques. Renew. Sustain. Energy Rev. 2016, 53, 720-732. [CrossRef]

22. Doroudchi, E.; Alanne, K.; Okur, Ö.; Kyyrä, J.; Lehtonen, M. Approaching net zero energy housing through integrated EV. Sustain. Cities Soc. 2018, 38, 534-542. [CrossRef]

23. Eid, C.; Codani, P.; Perez, Y.; Reneses, J.; Hakvoort, R. Managing electric flexibility from Distributed Energy Resources. Renew. Sustain. Energy Rev. 2016, 64, 237-247. [CrossRef]

24. Huda, M.; Koji, T.; Aziz, M. Techno Economic Analysis of Vehicle to Grid (V2G) Integration as Distributed Energy Resources in Indonesia Power System. Energies 2020, 13, 1162. [CrossRef]

25. Berckmans, G.; Messagie, M.; Smekens, J.; Omar, N.; Vanhaverbeke, L.; van Mierlo, J. Cost projection of state of the art lithium-ion batteries for electric vehicles up to 2030. Energies 2017, 10, 1314. [CrossRef]

26. Islam, E.S.; Moawad, A.; Kim, N.; Rousseau, A. Vehicle electrification impacts on energy consumption for different connected autonomous vehicle scenario runs. World Elect. Veh. J. 2020, 11, 9. [CrossRef]

27. Hannan, M.A.; Hoque, M.M.; Hussain, A.; Yusof, Y.; Ker, P.J. State-of-the-Art and Energy Management System of Lithium-Ion Batteries in Electric Vehicle Applications: Issues and Recommendations. IEEE Access 2018, 6, 19362-19378. [CrossRef]

28. Lu, L.; Han, X.; Li, J.; Hua, J.; Ouyang, M. A review on the key issues for lithium-ion battery management in electric vehicles. J. Power Sources 2013, 226, 272-288. [CrossRef] 